\title{
Analysis of rotors' critical mode of operation to be employed in the design of a wind generation control unit
}

\author{
Alina Fazylova ${ }^{1}$, Gani Balbayev ${ }^{2 *}$, Diana Ilieva $^{3}$, and Madina Aliyarova ${ }^{4}$ \\ ${ }^{1}$ A. Burkitbaev Institute of Industrial Engineering, Satbayev University, Almaty, Kazakhstan \\ ${ }^{2,4}$ Almaty University of Power Engineering and Telecommunication, Almaty, Kazakhstan \\ ${ }^{3}$ University of Telecommunications and Post, Sofia, Bulgaria
}

\begin{abstract}
This paper gives an overview and comparative characteristics of the main rotors available today, with properties suitable for the climatic conditions of Almaty and Almaty region, along with their critical mode of operation. A number of studies is carried out analysing the intrinsic features and capabilities of rotors, through which the problem of choosing an optimal rotor model for the subsequent design of a wind generator control unit is solved. One of these studies is a computer simulation of the main existing rotors operating in the same climatic conditions. The selected model must fully comply with the given environmental conditions of the selected area, in which the maximum wind speed and its critical value are set for all the studied rotor models. Thanks to the comparative studies on the technical characteristics of the most commonly used rotors, as well as to the modelling results, conclusions are drawn for the most effective and optimal choice to be employed in the design of a wind generator for the climatic conditions of the Almaty region.
\end{abstract}

\section{Introduction}

Currently, the whole world is in search of new energy sources, since the main energy sources used at this time lead to irreversible pollution of the environment and pose a serious threat to humanity and the ecology of the entire planet. In addition, the demand for energy is growing every year, so it is necessary to look for new, more environmentally friendly and inexpensive energy sources. There are many different environmental energy sources in nature, including wind energy. Since the generation of wind generators with characteristics suitable for certain natural and climatic regions is the most productive and, most importantly, safe way to use wind flow energy, it is necessary to work out in more detail the choice of rotors for the subsequent design of the wind generator control unit.

We selected the Darrieus Rotor as the main turbine under study, since the main results of the work [1] are suitable for the climatic conditions of the city of Almaty and the Almaty region. Patented by French aviation engineer Georges Jean-Marie Darrieus in 1931, the Darrieus wind turbine is often called the "egg whisk" because of its appearance. It consists of a few vertically directed blades that rotate around a Central axis. In [1], it was found that by adjusting certain parameters, it is possible to increase the efficiency and a several energy

${ }^{*}$ Corresponding author: gani_b@mail.ru 
indicators. However, as soon as important technical requirements for wind turbines are taken into account (for example, strength and wear resistance, gear ratio, requirements for bearings, generator), the limit of the amount of energy that can be obtained from wind energy is reduced to $10-30 \%$ of the actual wind energy. This limit is called the "capacity factor", which is unique for each type of wind turbine. Based on 3D modelling, it is possible to calculate the power coefficient depending on the speed [2]. There are also developments on the study of a vertical-axis wind generator at Nanyang University of Technology (Singapore), where comparative characteristics of the experimental data of the wind tunnel and output parameters are obtained by means of simulation [3]. This work allows us to verify the correctness of the selected method for the study of rotors. There are also developments in aerodynamic experimental studies [4]. Their main purpose is to measure the pressure distribution in different places of the blades of the wind turbine and to measure the flow through the turbine. The main measurement errors and measurement uncertainty are also discussed. This explains the difficulty in determining the angle of attack and dynamic pressure. This paper presents as well the results of studies of existing rotors in a critical mode of operation for the subsequent development of a system of control units for optimizing the operation of a wind generator. The critical mode of operation involves the operation of a wind generator at the maximum permissible value of wind speed. The results of research on the climatic conditions of the selected area in the Almaty region (Kazakhstan) are used. Based on the available and obtained data, a specific family of rotors are selected for the subsequent construction of a complete control system.

\section{Virtual experiment}

During the experiment we set the same boundary conditions for all measurements, one of which the wind speed of $35 \mathrm{~m} / \mathrm{s}$ - a critical value for the city of Almaty [5]. The others relate to the turbine rotating blades - all made from the same material - steel, with rotor diameter of $3 \mathrm{~m}$ and length of a single blade $4 \mathrm{~m}$.

A basic modelling has been formulated to characterize both its design and operation in [6] and main design variables and constraints have been selected by referring to a practical application as a speed reducer on a small windmill [7].

With environmental studies for the city of Almaty, the vertical-axis wind generators are the optimal type of wind generators for the city of Almaty and the Almaty region. Therefore, the main vertically axial rotor models were selected for research [8]. All rotor research and modelling have been conducted using SolidWorks software.

The first model under study was the H-type Darrieus rotor [9]. A 3D model with the distribution of the wind flow over the blades is shown in Fig. 1. The flow entering the rotor is shown on the right, and the flow coming out — on the left. The colours show the distribution of the wind flow acting on the rotor. Since the study is carried out at the maximum permissible value of wind speed, a flow of $35.007 \mathrm{~m} / \mathrm{s}$ has been set, which is shown in red. Such a significant speed can be reached in the presence of flat terrain [10].

In the figure, the red arrow indicates the space where the wind flow does not exert pressure on the rotor. The negative value of the wind speed (marked in blue in the figure) shows the flow repelling from the rotor opposite to the direction of the reference. The simulation results were obtained using SolidWorks software. This program allows to automatically calculate all parameters and display graphs.

Figure 2 shows the rotor dynamic characteristics in a normalized form at the start of the rotor for 80 iterations, where the $\mathrm{Y}$ axis normalizes from 0 to 1 such parameters as pressure acting on different parts of the wind turbine, wind speed, turbulence and power. In the figure, the graph of the pressure change acting on the blades is shown in blue, the graph of the pressure change on the main axis is red, the pressure acting on the entire installation is 
green; gray color is for turbulence, the speed of the air flow is indicated in yellow (that is, its conversion into electricity); turquoise color shows the flow rate acting along the $\mathrm{Z}$ axis (it does not actually matter much, since the main flow is directed along the Y axis), dark green - the force acting on the blades of the wind turbine. Black shows the maximum dynamic pressure on the blades, orange - the total maximum pressure on the entire turbine, pink - the maximum speed along the $\mathrm{Y}$ axis, gray - the maximum speed along the $\mathrm{Z}$ axis, dark blue - the maximum pressure on the blades. Maximum values do not play a role in this study. Since the study is dynamic, iterations are indicated along the $\mathrm{X}$ axis. One iteration corresponds to 1 second. Their actual values are shown in Figure 3.

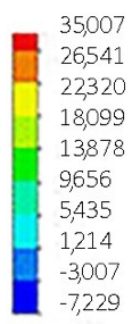

Velocity $(Y)[\mathrm{m} / \mathrm{s}]$

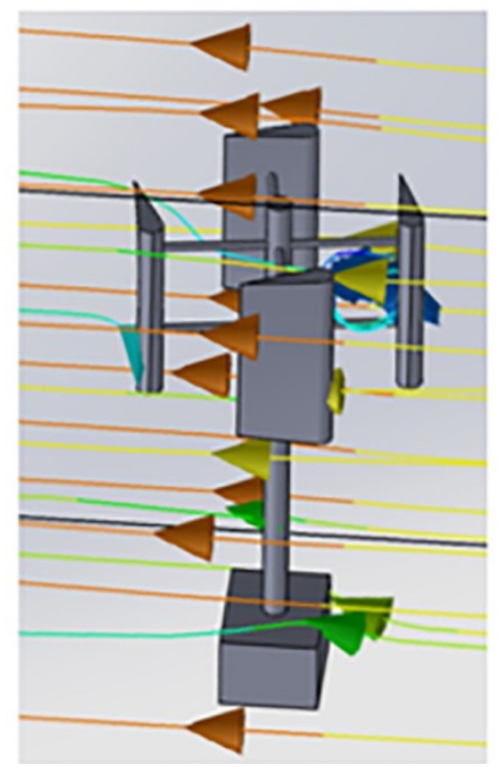

Fig. 1. 3D model with the distribution of the wind flow over the blades.

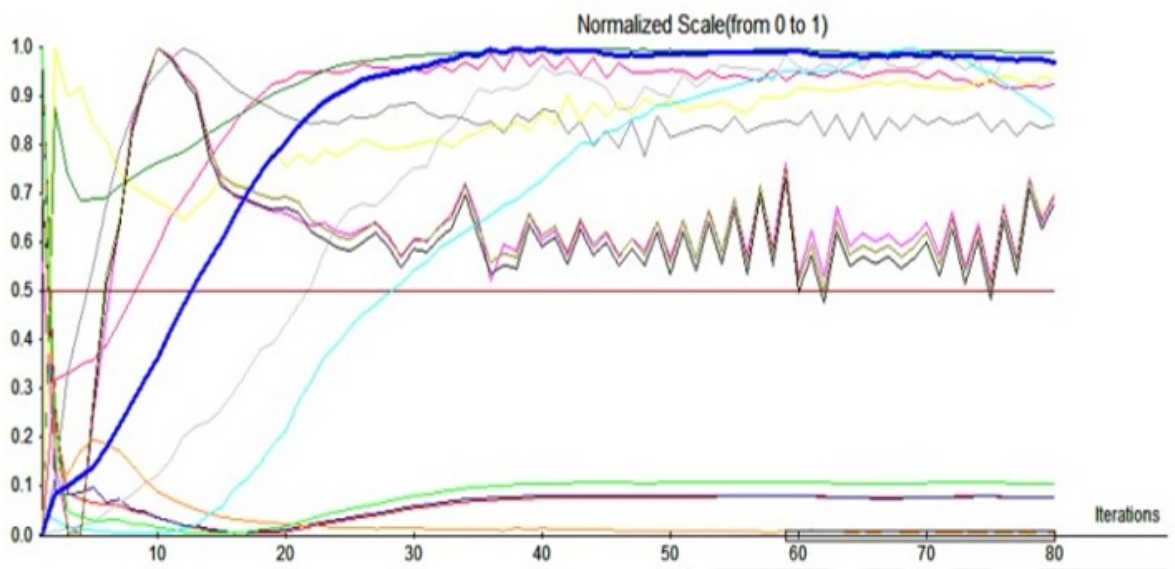

Fig. 2. Simulation plots of the wind flow. 


\begin{tabular}{|c|c|c|c|c|}
\hline Name & Current Value & Progress & Criterion & Averaged Value \\
\hline GG Av Dynamic Pressure 1 & 267.971 Pa & Achieved (IT = 41) & $2.97306 \mathrm{~Pa}$ & $268.243 \mathrm{~Pa}$ \\
\hline GG Av Heat Flux 1 & $0 \mathrm{~W} / \mathrm{m}^{\wedge} 2$ & Achieved (IT = 40) & $0 \mathrm{~W} / \mathrm{m}^{\wedge} 2$ & $0 \mathrm{~W} / \mathrm{m}^{\wedge} 2$ \\
\hline GG Av Static Pressure 1 & $101370 \mathrm{~Pa}$ & Achieved (IT $=54)$ & $3.83442 \mathrm{~Pa}$ & $101370 \mathrm{~Pa}$ \\
\hline GG Av Total Pressure 1 & $101638 \mathrm{~Pa}$ & Achieved (IT $=54)$ & $4.51555 \mathrm{~Pa}$ & $101639 \mathrm{~Pa}$ \\
\hline GG Av Turbulence Intensity 1 & $7.10725 \%$ & Achieved (IT = 53) & $0.571865 \%$ & $7.07384 \%$ \\
\hline GG Av Velocity $(Y) 1$ & $20.1664 \mathrm{~m} / \mathrm{s}$ & Achieved (IT $=80)$ & $0.00255442 \mathrm{~m} / \mathrm{s}$ & $20.1659 \mathrm{~m} / \mathrm{s}$ \\
\hline GG Av Velocity $(Z) 1$ & $0.234487 \mathrm{~m} / \mathrm{s}$ & Achieved $(\mathrm{IT}=79)$ & $0.0297928 \mathrm{~m} / \mathrm{s}$ & $0.262034 \mathrm{~m} / \mathrm{s}$ \\
\hline GG Av Velocity 1 & $20.3726 \mathrm{~m} / \mathrm{s}$ & Achieved $(\mathrm{IT}=40)$ & $0.0230425 \mathrm{~m} / \mathrm{s}$ & $20.3754 \mathrm{~m} / \mathrm{s}$ \\
\hline GG Friction Force $(Y) 1$ & $9.3762 \mathrm{~N}$ & Achieved (IT = 42) & $0.204746 \mathrm{~N}$ & $9.38799 \mathrm{~N}$ \\
\hline GG Max Dynamic Pressure 1 & $592.499 \mathrm{~Pa}$ & Achieved (IT $=40)$ & $34.3555 \mathrm{~Pa}$ & $568.328 \mathrm{~Pa}$ \\
\hline GG Max Total Pressure 1 & $102188 \mathrm{~Pa}$ & Achieved (IT = 40) & $62.7313 \mathrm{~Pa}$ & $102194 \mathrm{~Pa}$ \\
\hline GG Max Velocity $(\mathrm{V}) 1$ & $31.1091 \mathrm{~m} / \mathrm{s}$ & Achieved (IT $=40)$ & $1.01021 \mathrm{~m} / \mathrm{s}$ & $30.5578 \mathrm{~m} / \mathrm{s}$ \\
\hline GG Max Velocity (Z) 1 & $19.6333 \mathrm{~m} / \mathrm{s}$ & Achieved $(\mathrm{IT}=40)$ & $1.09542 \mathrm{~m} / \mathrm{s}$ & $19.6183 \mathrm{~m} / \mathrm{s}$ \\
\hline GG Max Velocity 1 & $31.3689 \mathrm{~m} / \mathrm{s}$ & Achieved $(\mathrm{IT}=40)$ & $0.943034 \mathrm{~m} / \mathrm{s}$ & $30.721 \mathrm{~m} / \mathrm{s}$ \\
\hline SG Av Total Pressure 1 & $101373 \mathrm{~Pa}$ & Achieved $(\mathrm{IT}=53)$ & $5.12907 \mathrm{~Pa}$ & $101373 \mathrm{~Pa}$ \\
\hline
\end{tabular}

Fig. 3. Simulation results of the Darrieus rotor.

The graph shows that such indicators as pressure, turbulence, the force acting on the blades from different sides, are normative. Of great interest in this study is the value of speed. The flow velocity acting on the rotor was set at $35 \mathrm{~m} / \mathrm{s}$, of which $20 \mathrm{~m} / \mathrm{s}$ cannot be used to convert electrical energy, that is, the graph shows $40 \%$ of the efficiency of this rotor. This is enough for the conditions of the city of Almaty and Almaty region. Nevertheless, the Darrieus rotor can withstand a wind speed of $44 \mathrm{~m} / \mathrm{s}$ in the idle position. The minimum wind speed is zero, respectively, the wind generator does not move. At a 0 30 iteration interval, the wind generator is in acceleration mode. In the range of 40-60 iterations along the $\mathrm{X}$ axis, a wind generator is installed and various fluctuations of indicators are possible here, which is a normal process. After 60 iterations, the wind generator is set for normal operation. Also, according to the results of creating this model, it would be fair to mention that there are problems with the self-starting of this rotor.

The second investigated model of a vertical-axis wind generator is a multi-blade wind generator [10]. Similar to the Darrieus rotor, identical initial parameters have been set in accordance with the climate analysis data for the city of Almaty and a 3D model has been constructed (Fig. 4). Simulation results have also been obtained (Fig. 5 and Fig. 6).

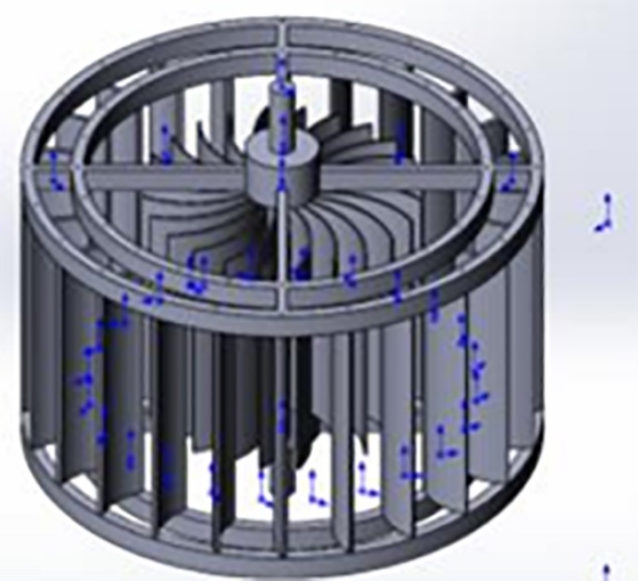

Fig. 4. 3D model of a multi-blade wind generator. 


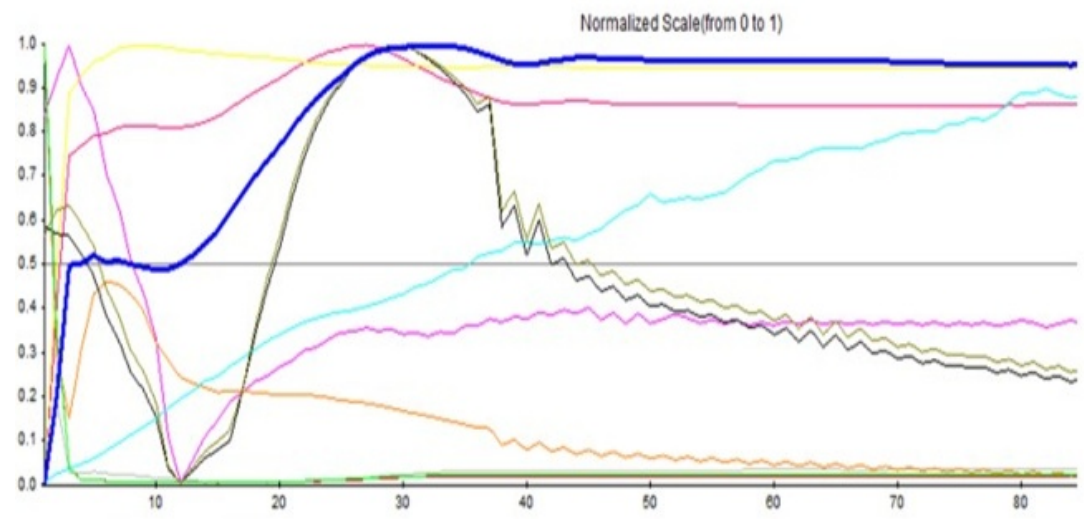

Fig. 5. Simulation plots with model in Fig.4.

\begin{tabular}{|c|c|c|c|c|}
\hline Name & Current Value & Progress & Criterion & Averaged Value \\
\hline GG Average Dynamic Pressure 1 & $308.537 \mathrm{~Pa}$ & Achieved (IT $=45)$ & $2.38038 \mathrm{~Pa}$ & $308.629 \mathrm{~Pa}$ \\
\hline GG Average Heat Flux 1 & $0 W / m^{\wedge} 2$ & Achieved $(I T=40)$ & $0 W / m^{\wedge} 2$ & $0 W / m^{\wedge} 2$ \\
\hline GG Average Static Pressure 1 & $101435 \mathrm{~Pa}$ & Achieved (IT $=49)$ & $32.8446 \mathrm{~Pa}$ & $101436 \mathrm{~Pa}$ \\
\hline GG Average Total Pressure 1 & $101744 \mathrm{~Pa}$ & Achieved $(I T=49)$ & $32.5171 \mathrm{~Pa}$ & $101745 \mathrm{~Pa}$ \\
\hline GG Average Turbulence Intensity 1 & $6.12699 \%$ & Achieved (IT = 113) & $0.443678 \%$ & $5.94674 \%$ \\
\hline GG Average Velocity $(n) 1$ & $21.214 \mathrm{~m} / \mathrm{s}$ & Achieved (IT = 40) & $0.0237198 \mathrm{~m} / \mathrm{s}$ & $21.2147 \mathrm{~m} / \mathrm{s}$ \\
\hline GG Average Velocity 1 & $21.6939 \mathrm{~m} / \mathrm{s}$ & Achieved (IT $=56)$ & $0.0638448 \mathrm{~m} / \mathrm{s}$ & $21.6923 \mathrm{~m} / \mathrm{s}$ \\
\hline GG Maximum Dynamic Pressure 1 & $761.472 \mathrm{~Pa}$ & Achieved (IT = 68) & $104.332 \mathrm{~Pa}$ & $766.457 \mathrm{~Pa}$ \\
\hline GG Maximum Total Pressure 1 & $104035 \mathrm{~Pa}$ & Achieved (IT = 58) & $440.821 \mathrm{~Pa}$ & $104042 \mathrm{~Pa}$ \\
\hline GG Maximum Velocity ( $M) 1$ & $35.2356 \mathrm{~m} / \mathrm{s}$ & Achieved (IT = 40) & $1.36812 \mathrm{~m} / \mathrm{s}$ & $35.2776 \mathrm{~m} / \mathrm{s}$ \\
\hline GG Maximum Velocity 1 & $35.5836 \mathrm{~m} / \mathrm{s}$ & Achieved $(\mathrm{IT}=68)$ & $2.08425 \mathrm{~m} / \mathrm{s}$ & $35.6268 \mathrm{~m} / \mathrm{s}$ \\
\hline SG Average Total Pressure 1 & $101175 \mathrm{~Pa}$ & Achieved (IT $=53$ ) & $21.5578 \mathrm{~Pa}$ & $101173 \mathrm{~Pa}$ \\
\hline
\end{tabular}

Fig. 6. Simulation results of a multi-blade wind generator.

Since the wind flow is set along the $\mathrm{Y}$ axis, the main energy is distributed on this axis, a wind speed of $0.23 \mathrm{~m} / \mathrm{s}$ can be neglected as in the previous study. The graph shows that the maximum speed with which the wind generator works effectively is $21 \mathrm{~m} / \mathrm{s}$, which is $1 \mathrm{~m} / \mathrm{s}$ more than for the Darrieus rotor. But this indicator is not paramount for the conditions of the city of Almaty and the Almaty region. The minimum wind speed as well as for the Darrieus rotor is zero. At the interval 0-5 iteration, the wind generator is in acceleration mode. In range of 5-30 iterations, small fluctuations are observed, but they do not greatly affect the operation of the wind generator and we can say that after the 5th iteration the wind generator works in normal mode. The efficiency of a multi-blade wind generator is $50 \%$ [12]. Also, the results of creating this model give us reasons to deduce that the wind generator can work at low speeds, as it accelerates quickly enough. That is, if the Darrieus rotor accelerates to 60 iterations, then a multi-blade wind generator takes 5 iterations. Among the shortcomings of this model, one can single out the cost of materials for constructing a rotor, since it has two rows of 12 (or more) blades each.

The third investigated model of a vertical-axis wind generator is the Magen Air Rotor System (MARS) [13]. Similarly to previous studies, identical initial parameters were set in accordance with the analysis of climatic conditions for the city of Almaty and a 3D model was constructed with the selected wind flow along the $Y$ axis from the bottom up (Fig. 7). 


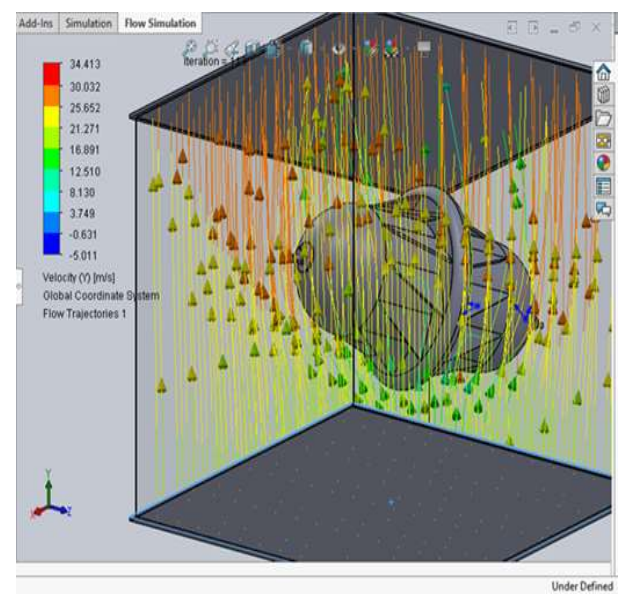

Fig. 7. 3D model with the selected wind flow.

\section{Conclusion}

Thus, for the study of rotors in a critical operating mode, the main representatives of different families of vertically axial wind generators were selected. The simulation results show that the Darrieus rotor is a slow running model of a wind generator, and even with the maximum allowable wind value applied to it accelerates very slowly. If the Darrieus rotor accelerates to 60 iterations, the multiblade wind generator accelerates to 5 iterations (12 times slower than the multiblade wind generator). During the simulation it has been found that the Darrieus rotor operates efficiently at $20 \mathrm{~m} / \mathrm{s}$, and the multi-blade wind generator is capable of working at $21 \mathrm{~m} / \mathrm{s}$. This means that the limit for efficient operation of a multiblade wind generator is higher than that of the Darrieus rotor. But this indicator is of low priority as there are practically no such blustery winds in the studied region. Thus, according to the modelling results, we can conclude that in the conditions of the Almaty region a multi-blade wind generator will work more efficiently and more reliably than the other studied models of vertical-axis wind generators.

\section{References}

1. K. S. Pyankov, Mathematical modeling of flows in wind turbines with a vertical axis / //Fluid Dynamics, №. 2, vol. 49, pp. 249-258, (2014)

2. D.V. Korobatov, A.S. Martyanov, E.S. Bodrova, S.A. Chetoshnikov, Study of the aerodynamic characteristics of a micro-wind power plant, Journal of South Ural State University (National Research University)", ESaC. №1(34) (2017)

3. S. Roy, U.K. Saha, Wind tunnel experiments of a newly developed two-bladed Savoniusstyle wind turbine. Appl Energy 137: pp.117-125, (2015)

4. J. G. Schepers, S. J. Schreck, Aerodynamic measurements on wind turbines, wires Energy and Environment/Volume 8, Issue 1 (2018)

5. A record figure reached power generation in Kazakhstan. ww.zakon.kz/kazakhstan/4477173.html (visited on 03.01.2020)

6. G. Balbayev, M. Ceccarelli, Design and characterization of a new planetary gear box, Mechanisms and Machine Science No.17, pp. 91-98 (2014) 
7. G. Balbayev, G. Carbone, A dynamic simulation of a novel continuous variable transmission, Mechanisms and Machine Science No.17, pp. 109-116 (2014)

8. Official site of the President of The Republic of Kazakhstan. www.akorda.kz/ru/republic_of_kazakhstan [02.01.2020]

9. Yu. V. Kozhukhov, A.A. Lebedev, A.M. Danylyshyn, E.V. Davletgareev. Auditing the characteristics of wind generators using CFD modeling on a supercomputer, a magazine. No. 7 (107), pp. 81-87 (2016)

10. Terziev A., Analysis of the possibilities of using reference wind measurements in the calculation of energy production from wind farms on low complex terrains, E3S Web Conf., Volume 112, 2019, https://doi.org/10.1051/e3sconf/201911202004

11. J. Twidell, A. Weir. Wind Energy // Renewable Energy - M .: Energoatomizdat, 393 p. ISBN 5-283-02469-5 (1990)

12. B. Saravanan, S. D. Sikrid, P. Kothari. A solution to the unit commitment problem - a review, Front. Energy, no. 7(2), p. 223-236 (2013)

13. R. D. Zimmerman, C. E. Murillo-S'anchez. Matpower Optimal Scheduling Tool MOST 1.0 User's Manual, Power Systems Engineering Research Center (PSerc) (2016) 